\title{
SPME-GC-FID Method Development for Analyzing Cyclohexanone Hydrogenation Products
}

\author{
Adriana R. A. Coelho, Ione M. F. Oliveira and Zenilda L. Cardeal* \\ Departamento de Química, Instituto de Ciências Exatas, Universidade Federal de Minas Gerais, \\ Av. Antônio Carlos, 6627, 31270-901 Belo Horizonte-MG, Brazil
}

\begin{abstract}
Este trabalho apresenta o desenvolvimento de um método simples, rápido e preciso para análise dos produtos da hidrogenação eletrocatalítica da ciclohexanona com a técnica de microextração em fase sólida, usando cromatografia a gás com detector de ionização por chama. A otimização preliminar do método foi realizada através de ferramentas quimiométricas. Os resultados de LOD e LOQ foram $0,50 \%$ de conversão ou $0,78 \mathrm{mg} \mathrm{L}^{-1}$ e $1,20 \%$ de conversão ou 1,86 $\mathrm{mg} \mathrm{L}^{-1}$, respectivamente. A curva analítica demonstra boa linearidade $\left(\mathrm{R}^{2}=0,9936\right)$.
\end{abstract}

This work presents a method development for analyzing electrocatalytic hydrogenation products of cyclohexanone with the simple, fast and accurate SPME, coupled with classic gas chromatographic methods using flame ionization detection. Preliminar method optimization was made using chemometric tools. LOD and LOQ obtained were $0.50 \%$ conversion or $0.78 \mathrm{mg} \mathrm{L}^{-1}$ and $1.20 \%$ conversion or $1.86 \mathrm{mg} \mathrm{L}^{-1}$ respectively. The analytical curve obtained displays good linearity $\left(\mathrm{R}^{2}=0.9936\right)$.

Keywords: SPME, HEC, cyclohexanone, chemometrics

\section{Introduction}

Both heterogeneous and homogeneous catalysis play an important role in the fragrance and flavor industry. Catalytic hydrogenations are usually heterogeneous, because the catalyst can be easily separated and recycled. Its main use is the reduction of olefins, but it also applies to the reduction of carbonyl compounds. ${ }^{1}$

The hydrogenation reactions of unsaturated compounds bear great interest for modern industry. Although various catalytic and electrocatalytic processes have been presented that allow selective hydrogenation of unsaturated organic compounds, there is still room for improvement, particularly in the field of electrocatalysis. ${ }^{2}$

In most studies on the field of electrocatalytic hydrogenation $(\mathrm{ECH})$ and catalytic hydrogenation $(\mathrm{CH})$, the method applied for the analysis of the reaction products or media is gas chromatography, which can sometimes be coupled with a spectrometric method. In general, the reaction product is separated from the aqueous media by liquid-liquid extraction.

The electrocatalytic hydrogenation $(\mathrm{ECH})$ of phenol at a Raney nickel cathode, for instance, was studied in

*e-mail: zenilda@ufmg.br aqueous and hydro-organic solutions. At $30^{\circ} \mathrm{C}$, without surfactants, cyclohexanol was obtained with low or medium yields. The progress of the electrolysis was followed by gas-liquid chromatography with a FID detector and a DBWax capillary column. Aliquots $(0.5 \mathrm{~mL})$ from the aqueous catholyte were extracted with ethoxyethane, after addition of $1 \mathrm{~mL}$ of saturated $\mathrm{NaCl}$ solution and acidification ( $\mathrm{pH}$ ca.1) with $\mathrm{HCl}$. The products were identified by comparing their retention times with those of authentic samples, using $n$-heptadecane or dodecane as internal standard method. With hydro-organic solutions, prior to the extraction, ethanol was removed by distillation at atmospheric pressure and quantitatively analyzed by GLC. The ethoxyethane was then dried $\left(\mathrm{MgSO}_{4}\right)$, evaporated under vacuum and the mass balance was calculated from the weight of the crude product. In some experiments the crude product was also analysed by ${ }^{1} \mathrm{H}$ NMR spectroscopy. ${ }^{3}$

The electrocatalytic hydrogenation of cyclohexanone has been investigated with catalytic powder particles made of metal nano-aggregates deposited on a nonconductive material such as activated carbon and alumina. The brief contact of the powder particles with a porous carbon cathode was sufficient to form adsorbed hydrogen on the metallic nano-aggregates through water electrolysis and initiate the electrohydrogenation process. Samples of $1 \mathrm{~mL}$ 
were removed at different times during the electrolysis. Cyclohexanone and cyclohexanol were extracted in a solution of ethyl acetate containing $\mathrm{HCl}, \mathrm{NaCl}$ and ISTD (3-methylcyclohexa-1-ol in water). The aqueous phase was frozen on an acetone $/ \mathrm{CO}_{2}$ ice mix. The organic part was removed, dried and injected in a gas chromatograph system, equipped with FID detector to further identify the organic compounds. ${ }^{4}$

A modified electrode (ME) covered with poly[allyl-ether-p-(2-aminoethyl)-phenol] film containing platinum particles was prepared and used for the electrohydrogenation of several carbonylic compounds. The ECH of cyclohexanone, for example, took $24 \mathrm{~h}$ at first, obtaining a $65.3 \%$ yield, and the use of the modification led to a $88.5 \%$ yield, obtained after $16 \mathrm{~h}$ of ECH at $-0.6 \mathrm{~V}$ potential versus satured calomel electrode (SCE). In this study, to isolate the reaction products, the final solution was neutralized with $\mathrm{NaHCO}_{3}$ and $\mathrm{CH}_{2} \mathrm{Cl}_{2}$ was used for extraction. After solvent evaporation, the products were analyzed by GC-FID. Isophorone (3,5,5-trimethylcyclohex2-en-1-one) and cyclohex-2-en-1-one products were analyzed by ${ }^{1} \mathrm{H}$ NMR, using a Brüker AC-80 (80 MHz) spectrometer. $^{5}$

In another study, the electrocatalytic hydrogenation of cyclohexanone was used to test the performance (amount of cyclohexanol versus time of generated electrolysis at constant current) of original and versatile new materials for the electrocatalytic hydrogenation of organic substracts. The data is measured and compared for the various bonded organic functions of the modified silica surface. The ECH yield is defined as the relative amount (\%) of cyclohexanol generated in the solution for a given Faradic charge. The results are presented as the sum of the amount of cyclohexanol and cyclohexanone being $100 \%$. The hydrogenation efficiency reached over $80 \%$ for a $336 \mathrm{C}$ charge applied.

During the electrocatalytic hydrogenation process (ECH), samples of $500 \mu \mathrm{L}$ were withdrawn from the catholyte, saturated with sodium chloride, and then extracted with $1 \mathrm{~mL}$ of chloroform. The solution was dried using anhydrous sodium sulfate and analyzed by GC-FID. ${ }^{6}$

The catalytic and electrocatalytic hydrogenation of benzophenone (diphenylmethanone) were performed in aqueous ethanol onto $10 \%(\mathrm{~m} / \mathrm{m}) \mathrm{Pd}$-alumina supported catalyst and finely divided Pd catalyst. Quantitative analyses were carried out by gas chromatography (GC-MS). Aliquots were removed from the cathodic compartment at different times of electrolysis (for $\mathrm{ECH}$ ) or from a bulk solution at different times of reaction (for $\mathrm{CH}$ ). The solution was treated with $\mathrm{NaCl}$ and chloroform, the organic phase was removed, dried and injected in the gas chromatograph. ${ }^{7}$

The use of SPME improves the efficiency of the analysis of volatile organic compounds in many different samples: it produces rapid extraction and allows direct introduction in the analytical equipment; it does not disturb the living system equilibrium and provides better analytical performance in lesser time; it is easily automated and solvent-free.

In 2003, a method for the direct determination by gas chromatography-mass spectrometry (GC-MS) analysis of the products from the limonene (1-methyl-4-prop-1en-2-yl-cyclohexene) disproportionation obtained from the catalytic hydrogenation of castor oil was proposed. To monitor the hydrogenated products formed on the reaction by (GC-MS) it would be necessary to transesterify many small samples several times during the reaction course. In order to avoid those steps, a headspace solid-phase microextraction (SPME) method followed by GC-MS was optimized.

SPME was carried out in the headspace mode with a $100 \mu \mathrm{m}$ polydimethylsiloxane (PDMS) fiber. Hydrogenation reaction was performed in a $50 \mathrm{~mL}$ twonecked round-bottomed flask with a thermometer and a reflux condenser for $1 \mathrm{~h}$ at $178^{\circ} \mathrm{C}$. Hexane was added to the flask, immediately followed by centrifugation. The extract was hot filtered, for the separation of $\mathrm{Pd} / \mathrm{C}$, and the hydrogenated product was precipitated by freezing. The liquid phase was separated and stored at $4{ }^{\circ} \mathrm{C}$ and the hydrogenated product was dried and also stored. SPMEGC-MS was found to be a simple and sensible method for the evaluation of the volatile compounds formed on the disproportionation of limonene during the hydrogenation of castor oil, and proved to be a good method to follow the intermediate products of disproportionation of limonene as an indicator of the hydrogenation of the Castor oil. ${ }^{8}$

Solid-phase microextraction has also been used for identifying, quantifying and following the evolution of intermediate products of octan-1-ol degradation by photocatalytic and ultrasound processes, inducing mainly the same active species, and the photocatalytic degradation of the organophosphorus insecticides ethyl parathion (diethoxy-(4-nitrophenoxy)-sulfanylidene-phosphorane) and fenthion (dimethoxy-(3-methyl-4-methylsulfanylphenoxy)-sulfanylidene-phosphorane) in aqueous titanium dioxide suspensions under simulated solar irradiation. ${ }^{9,10}$

Publications cited above describe superficially the analytical procedure of obtained products. Although the main target of those studies is the reaction observation or optimization, yield results should be measured in a reliable manner because of their importance in these researches. 
In this paper, a fast direct SPME method is proposed for GC-FID analysis of the electrocatalytic hydrogenation product of cyclohexanone, cyclohexanol. Such idea aims to reduce the steps of sample preparation, as well as to reduce solvent use, and to give a more accurate response for analyzing the progress of the reaction by introducing analytical curve, precision methods (variation coefficient intra and inter essay) and quantification limit tests for specific analysis of substracts and products from a reaction. It is considered that similar methods can be developed in the future, regarding any other substracts that could undergo electrocatalytic hydrogenation, reaching more reliable results.

\section{Experimental}

\section{Apparatus}

Electrochemical measures were made using a PGSTAT-20 potenciostat, from AutoLab (Eco Chemie, Netherlands), connected to the corresponding software (General Purpose Electrochemical System, GPES) through an ISA-IF020 interface. A three-electrode cell was used for the hydrogenation. The reference electrode used was Ag; Pt was the auxiliary electrode and the working electrode was a modified electrode, prepared over a carbon felt $(10 \mathrm{~mm} x$ $10 \mathrm{~mm} \times 3 \mathrm{~mm}$ ) by polymerization of $n$-(4-carboxybenzyl)pyrrole monomer followed by deposition of nickel particles, as described by Oliveira. ${ }^{11}$

Chromatographic analysis were performed with a HP PAS $/ 5(25 \mathrm{~m} \times 0.32 \mathrm{~mm} \times 0.52 \mu \mathrm{m})$ capilar column (Hewlett Packard, Palo Alto, USA), on a Shimadzu GC-17 (Kyoto, Japan) gas chromatographer with flame ionization detector. The Class-CR10 software was used for data treatment.

SPME was carried out in $22 \mathrm{~mL}$ glass vials sealed with Teflon septa and aluminum caps, using a $100 \mu \mathrm{m}$ PDMS polydimethylsiloxane fiber and manual supporte from Supelco (Bellefonte, USA). The temperature was controlled with a system consisting of a metallic block with two cavities: one for the vial and one for a thermometer, the block being placed over an electrical stirrer hot plate.

All the chemometric data management was performed with the aid of the Microsoft Excel ${ }^{\circledR}$ worksheets designed by Teófilo and Ferreira. ${ }^{12}$

\section{Materials and reagents}

High purity deionized (MilliQ) water was the solvent both in chromatographic and electrochemical experiments. Potassium chloride, from Merck, was used as electrolyte for the hydrogenation. Sodium chloride, also Merck, was used in $5 \%(\mathrm{~m} / \mathrm{v})$ concentration in all SPME solutions. Cyclohexanone and cyclohexanol were HPLC grade.

All the electrochemical experiments were performed under nitrogen $99 \%$ pure atmosphere (White Martins, Belo Horizonte, Brazil).

\section{Electrocatalytic hydrogenation procedure}

The coulommetric electrocatalytic hydrogenation was conduct on a $17 \mathrm{~mL}$ cell containing $15 \mathrm{~mL}$ aqueous $\mathrm{KCl}$ $0.5 \mathrm{~mol} \mathrm{~L}^{-1}$ and $240 \mu \mathrm{L}\left(2.32 \mathrm{mmol} \mathrm{L}^{-1}\right)$ of cyclohexanone, under a $-1.35 \mathrm{~V}$ potencial. Samples of $0.5 \mathrm{~mL}$ were taken after $445 \mathrm{C}$ and $990 \mathrm{C}$ was applied ( 2 and 4 electrons per molecule, respectively).

\section{SPME samples}

Preliminary SPME and GC setup studies were carried out in a cyclohexanol/cyclohexanone diluted solution containing $0.08 \mathrm{mmol} \mathrm{L}^{-1}$ of each reagent.

To elaborate the analytical curve, $50 \mathrm{~mL}$ solutions were prepared using cyclohexanol in quantities that would reproduce 0 to $98.1 \%$ hydrogenation of the $2.32 \mathrm{mmol}$ of cyclohexanone in the proposed reactional media. The final concentrations in cyclohexanol were $0.77,1.55,3.10$, $6.20,15.49,77.46,9.14,19.05,37.95,75.91,114.02$ and $151.97 \mathrm{mg} \mathrm{L}^{-1}$. All solutions had the same cyclohexanone concentration, fit to represent $50 \%$ of the total content in the reactional media, $75.9 \mathrm{mg} \mathrm{L}^{-1}$, in $5 \%(\mathrm{~m} / \mathrm{v})$ sodium chloride aqueous solution. A sample blank solution was also prepared for analytical curve, LOD and LOQ studies, and it was cyclohexanone and cyclohexanol free.

The $0.5 \mathrm{~mL}$ reaction samples obtained from the hydrogenation process were diluted $1: 100 \mathrm{~mL}$ in $5 \%(\mathrm{~m} / \mathrm{v})$ sodium chloride aqueous solution for analysis.

In all analysis, $15 \mathrm{~mL}$ solution were added to the vial for the SPME extraction. The vial was kept at $45^{\circ} \mathrm{C}$ during $5 \mathrm{~min}$ for the SPME direct extraction followed by a thermal desorption at $220{ }^{\circ} \mathrm{C}$ for $102 \mathrm{~s}(1.7 \mathrm{~min})$.

\section{Parameters of the chromatographic analysis}

After preliminary studies, the optimized oven temperature program began at $52{ }^{\circ} \mathrm{C}$, held for $16 \mathrm{~min}$ and was then raised to $90{ }^{\circ} \mathrm{C}$ at $15^{\circ} \mathrm{C} \mathrm{min}{ }^{-1}$, and held for one minute at this temperature. The column flow was $1 \mathrm{~mL} \mathrm{~min}^{-1}$. Hydrogen ultra pure was used as carrier gas. The detector used nitrogen, syntethic air and hydrogen with 30:300:30 $\mathrm{mL} \mathrm{min}^{-1}$ flows respectively. The detector temperature was held $230{ }^{\circ} \mathrm{C}$ and the injector, $220{ }^{\circ} \mathrm{C}$ in the splitless mode for $102 \mathrm{~s}$. 


\section{Chemometrics}

Two experimental designs were proposed to optimize the SPME parameters. First, a $2^{3}$ fatorial design with 5 replicates center points (Table 1).

Table 1. Factors and levels for the $2^{3}$ factorial design

\begin{tabular}{lccc}
\hline Factor & $\begin{array}{c}\text { Lower } \\
\text { level }\end{array}$ & $\begin{array}{c}\text { Central } \\
\text { Point }\end{array}$ & $\begin{array}{c}\text { Higher } \\
\text { level }\end{array}$ \\
\hline 1 (extraction time) $/ \mathrm{min}$ & 2 & 16 & 30 \\
2 (extraction temperature) $/{ }^{\circ} \mathrm{C}$ & 25 & 45 & 65 \\
3 (desorption time) $/ \mathrm{s}$ & 30 & 60 & 90 \\
\hline
\end{tabular}

From that, a central composite design (Table 2) was prepared. Only two factors were considered, based on the $2^{3}$ fatorial design results.

Table 2. Factors and levels for the central composite design

\begin{tabular}{lccccc}
\hline Factor & \multicolumn{5}{c}{ Level value } \\
\cline { 2 - 6 } & -1.41 & -1 & 0 & 1 & 1.41 \\
\hline 1 (extraction temperature) $/{ }^{\circ} \mathrm{C}$ & 45 & 55 & 80 & 105 & 115 \\
2 (desorption time) $/ \mathrm{s}$ & 18 & 30 & 60 & 90 & 102 \\
\hline
\end{tabular}

\section{Validation}

Analytical curve, precision methods (variation coefficient intra and inter essay) and quantification limit tests were made based on Eurachem recommendations. ${ }^{13}$ Two replicates of thirteen sample points were used to build the analytical curve, with the aid of Microsoft Excel® software. The precision method was investigated through seven consecutive replicates of three arbitrary points of the analytical curve for intra-essay studies, and analysis of the same three points along 7 days for the inter-essay studies. Finally, the detection and quantification limits were determined by 10 replicates of blank analysis, with values according to the mathematical expression suggested by Eurachem:

LOD $=$ sample blank mean value +3 standard deviations of the blank mean

$\mathrm{LOQ}=$ sample blank mean value +10 standard deviations of the blank mean

\section{Results and Discussion}

\section{Chemometrics}

From the data obtained by the $2^{3}$ factorial design (Table 3 ), we can observe that effect 1 , extraction time, is not relevant. It was further set to 5 minutes. Factors 2 and 3 show individual relevance, along with interactions between factors 1-2 and 2-3.

Table 3. Results obtained in the $2^{3}$ factorial design

\begin{tabular}{|c|c|c|c|c|c|}
\hline \multicolumn{3}{|c|}{ Effects } & \multirow{2}{*}{$\begin{array}{c}\text { Error } \\
50\end{array}$} & \multirow{2}{*}{$\begin{array}{l}\mathrm{t}(4) \\
75.9\end{array}$} & \multirow{2}{*}{$\frac{\mathrm{P}}{1.82 \times 10^{-}}$} \\
\hline Average $^{(a)}$ & 3812.84 & \pm & & & \\
\hline 1 & 19 & \pm & 128 & 0.15 & 0.889 \\
\hline $2^{\text {(a) }}$ & 382 & \pm & 128 & 2.97 & 0.041 \\
\hline $3^{(a)}$ & 657.5 & \pm & 128 & 5.12 & 0.0069 \\
\hline $12^{(\mathrm{a})}$ & -975.5 & \pm & 128 & 7.60 & 0.0016 \\
\hline 13 & 315 & \pm & 128 & 2.45 & 0.0702 \\
\hline $23^{\text {(a) }}$ & -981 & \pm & 128 & 7.63 & 0.0016 \\
\hline 123 & -56.5 & \pm & 128 & 0.43 & 0.6827 \\
\hline
\end{tabular}

${ }^{(a)}$ Relevant effects for significance level $(\alpha) 0.05$.

With the following step, central composite design, the results obtained (Table 4) show that the interaction between extraction temperature and desorption time is the most relevant factor.

Table 4. Results obtained in the central composite design

\begin{tabular}{lclcccc}
\hline \multicolumn{2}{c}{ Effects } & & & Error & $\mathrm{t}(2)$ & $\mathrm{P}$ \\
\cline { 1 - 2 } \cline { 5 - 6 } Average $^{(a)}$ & 3350 & \pm & & 89 & 37 & 0.0007161 \\
1 & -304.5 & \pm & & 237 & 1.28 & 0.3281319 \\
2 & -25.5 & \pm & & 237 & 0.107 & 0.9242536 \\
$12^{\text {(a) }}$ & -1341.5 & \pm & & 237 & 5.65 & 0.0299098 \\
\hline
\end{tabular}

${ }^{(a)}$ Relevant effects for significance level $(\alpha) 0.05$.

The quadratic equation obtained is able to explain $78.47 \%$ of the variance of the system.

$$
\begin{aligned}
& Z=3434.492+113.152 x+346.981 y+ \\
& 345.343 x^{2}-640.272 y^{2}-670.75 x y
\end{aligned}
$$

In this equation, $\mathrm{Z}$ is the response (peak area), $\mathrm{x}$ is the temperature of extraction and $y$ is the desorption time. The surface obtained by this quadratic equation displays a saddle point exactly under the conditions set as central point. The response increases both to the combination of higher temperature and lower desorption time, and lower temperature and higher desorption time. Since the system is aqueous, the decision was made to operate under the second combination of factors. This way, it was established that the best given conditions would be $45^{\circ} \mathrm{C}$ extraction temperature with $5 \mathrm{~min}$ extraction time and $102 \mathrm{~s}$ desorption time $(1.7 \mathrm{~min})$.

\section{Method validation}

The analytical curve obtained based on the peak intensity (see Table 5) displays good linearity $\left(\mathrm{R}^{2}=0.9936\right)$ in the analyzed range, leading to the function 
P.I. = 399.13 C,

where P.I means peak intensity (in $\mathrm{mV}$ ) and $\mathrm{C}$ means conversion $\%$.

Table 5. Analytical curve data for cyclohexanone hydrogenation

\begin{tabular}{cccc}
\hline Cyclohexanone & Concentration / & \multicolumn{2}{c}{ Peak intensity / mV } \\
\cline { 3 - 4 } convertion / & $\left(\mathrm{g} \mathrm{L}^{-1}\right)$ & $1^{\text {st }}$ response & $2^{\text {nd }}$ response \\
\hline 0.0 & 0.000 & 0 & 0 \\
0.5 & 0.077 & 850 & 693 \\
1.0 & 0.155 & 792 & 692 \\
2.0 & 0.310 & 1098 & 1102 \\
4.0 & 0.620 & 2761 & 2372 \\
5.9 & 1.549 & 1799 & 1728 \\
10.0 & 7.746 & 4781 & 4686 \\
12.3 & 0.914 & 3794 & 3594 \\
24.5 & 1.905 & 8866 & 8474 \\
49.0 & 3.795 & 17524 & 18835 \\
50.0 & 7.591 & 22699 & 19872 \\
73.6 & 11.402 & 28184 & 29665 \\
98.1 & 15.197 & 39364 & 40317 \\
\hline
\end{tabular}

The variation coefficients for the method indicate good precision, as seen in Table 6.

Table 6. Variation coefficients for the analysis of cyclohexanol

\begin{tabular}{lcc}
\hline Sample id & \multicolumn{2}{c}{ Variation coefficient } \\
\cline { 2 - 3 } & Inter-essay & Intra-essay \\
\hline P2 & $4 \%$ & $6 \%$ \\
P4 & $2 \%$ & $3 \%$ \\
P5 & $2 \%$ & $1 \%$ \\
\hline
\end{tabular}

The limit of detection obtained was $0.78 \mathrm{mg} \mathrm{L}^{-1}$ cyclohexanol $(0.50 \%$ convertion of total cyclohexanone available), while limit of quantification was $1.86 \mathrm{mg} \mathrm{L}^{-1}$ cyclohexanol (1.20\% convertion convertion of total cyclohexanone available). The total cyclohexanone is $152 \mathrm{mg} \mathrm{L}^{-1}$, given that the reactional media presents $2.32 \mathrm{mmol}$ of the substract in $15.0 \mathrm{~mL}$ solution and samples are to be diluted $1: 100$.

\section{Aplication of proposed method}

The hydrogenation results were very low. For 2 electrons per molecule, a $1.33 \%$ hydrogenation was accounted (2.06 $\mathrm{mg} \mathrm{L}^{-1}$ ). This sample was taken after $54 \mathrm{~min}$, when $445 \mathrm{C}$ passed through the system. For 4 electrons per molecule, $990 \mathrm{C}$, another $86 \mathrm{~min}$ were necessary, in a total time of $140 \mathrm{~min}$, and the hydrogenation product was still low: only $3.08 \%\left(4.78 \mathrm{mg} \mathrm{L}^{-1}\right)$.

\section{Conclusions}

Chemometric methods were successfully applied to optimize the SPME-GC-FID procedure to determine the electrocatalytic hydrogenation products of cyclohexanone. The analytical method developed showed good linearity, high precision and low detection and quantification limits, allowing its wide use, whatever were the hydrogenation results. The quantification is highly reliable due to the analytical curve.

\section{Acknowledgments}

The authors would like to thank Prof. Jean-Claude Moutet for donating the N-(4-carboxybenzyl)-pyrrol. CAPES (Coordenação de Aperfeiçoamento de Pessoal de Nível Superior, Brazil) is acknowledged for the financial support.

\section{References}

1. Chapuis, D. J.; Appl. Catal., A 2001, 221, 93.

2. St-Pierre, G.; Chagnes, A.; Bouchard, N.-A.; Harvey, P. D.; Brossard, L.; Ménard, H.; Langmuir 2004, 20, 6365.

3. Ilikti, H.; Rekik, N.; Thomalla, M.; J. Appl. Electrochem. 2002 , $32,603$.

4. Dubé, P.; Kerdouss, F.; Laplante, F.; Proulx, P.; Brossard, L.; Ménard, H.; J. Appl. Electrochem. 2003, 33, 541.

5. Lofrano, R. C. Z.; Madurro, J. M.; Abrantes, L. M.; Romero, J. R.; J. Mol. Catal. A: Chem. 2004, 218, 73.

6. Lofrano, R. C. Z.; Madurro, J. M.; Abrantes, L. M.; Romero, J. R.; Langmuir 2004, 20, 15.

7. Cirtiu, C. M.; Brisach-Wittmeyer, A.; Ménard, H.; Catal. Commun. 2007, 8, 751.

8. Schneider, R. C. S.; Baldissarelli, V .Z.; Martinelli, M.; von Holleben, M. L. A.; Caramão, E. B.; J. Chromatogr., A 2003, 985, 313.

9. Guillard, C.; Théron, P.; Pichat, P.; Pétrier, C.; Water Res. 2002, 36,4263 .

10. Sakkas, V. A.; Lambropoulou, D. A.; Sakellarides, T. M.; Albanis, T. A.; Anal. Chim. Acta 2002, 467, 233.

11. Oliveira, G. F.; MSc Dissertation, Universidade Federal de Minas Gerais, Brazil, 2004.

12. Teófilo, R. F.; Ferreira, M. M. C; Quim. Nova 2006, 29, 338.

13. Eurachem Guide; The Fitness for Purpose of Analytical Methods, a Laboratory Guide to Method Validation and Related Topics; LGC: Teddington, UK, 1998.

Received: June 18, 2008 Web Release Date: March 6, 2009 